University of Nebraska - Lincoln

DigitalCommons@University of Nebraska - Lincoln

1991

\title{
Aerospace Monitoring of Water Quality
}

Anatoly A. Gitelson

University of Nebraska - Lincoln, agitelson2@unl.edu

Ferenc Szilagyi

Water Resources Research Center, Budapest, Hungary

Follow this and additional works at: https://digitalcommons.unl.edu/natrespapers

Part of the Natural Resources and Conservation Commons

Gitelson, Anatoly A. and Szilagyi, Ferenc, "Aerospace Monitoring of Water Quality" (1991). Papers in Natural Resources. 232.

https://digitalcommons.unl.edu/natrespapers/232

This Article is brought to you for free and open access by the Natural Resources, School of at DigitalCommons@University of Nebraska - Lincoln. It has been accepted for inclusion in Papers in Natural Resources by an authorized administrator of DigitalCommons@University of Nebraska - Lincoln. 


\title{
AEROSPACE MONITORING OF WATER QUALITY
}

\author{
Anatoly Gitelson and Ferenc Szilagyi*
}

\author{
Ben-Gurion University; J.Blaustein Inst.for Desert Research \\ Sede-Boker Campus 84990 , Israel \\ *Water Resources Research Center, H-1453 Budapest, P.O.B. 27, Hungary
}

\section{ABSTRACT}

The potential of using remote sensing for the detection of chlorophyll-a (CHL), dissolved organic matter (DOM), and suspended matter (SM) concentrations in coastal and inland waters was investigated using measurements of (ir) radiance spectra along with simultaneous earth-reference data. The range of $\mathrm{CHL}$ was 0.1 to $350 \mu \mathrm{g} / 1$, SM was 0.1 to $43 \mathrm{mg} / 1$, and DOM absorption at the $380 \mathrm{~nm}$ was 0.1 to $10^{-1}$. Factor and signature analysis reveal allometric relationships between constituent concentrations $c_{k}$ and functions of

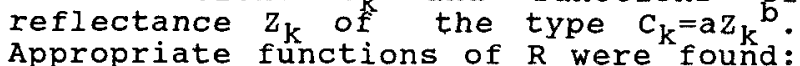
Appropriate functions of $\mathrm{R}$ were found: and $z_{\text {dom }}=\{R(480)+k[R(700) / R(675)]\} / R(630)$.' The maximum estimation errors were: CHL $3 \mu \mathrm{g} / \mathrm{l}$, DOM - $0.065 \mu \mathrm{gC} / \mathrm{l}$, and $\mathrm{SM}-4 \mathrm{mg} / \mathrm{l}$ Keywords: irradiance, optical properties.

\section{INTRODUCTION}

The main goal of this research is to establish remote sensing methods for estimating relevant water quality components. An improved solution for this problem is obtained by developing optical models of water bodies on the basis of relationships between (ir) radiance spectra and the simultaneously obtained earth-reference data. We developed a method for interpreting remotely sensed data from inland and coastal waters. These typically highly productive waters are a troublesome problem for remote sensing, because numerous suspensions (phytoplankton, detritus, non-organic suspended matter, yellow substance, etc.) vary in character and amount within short distances and time intervals, and can modify the upwelling visible radiation measured remotely [1-6].

\section{MATERIALS AND METHODS}

\section{Several}

(ir) radiance

\section{hundred} measurements were spectral conducted along with simultaneous ground-data references in the test areas [5-12]. Water quality samples were collected for measuring the total of phytoplankton $\mathrm{CHL}$ phaeopigments, and biomass, SM, DOM, absorption and scattering coefficients, in vivo excitation and emission fluorescence spectra of $\mathrm{CHL}$ and DOM [8,12]. Radiometric measurements were taken from either a boat or an aircraft including upwelling and downwelling spectral (ir) radiance at the wavelengths 430 to 750 , nm, laserstimulated fluorescence of DOM (at the 400 to $560 \mathrm{~nm}$ ) and CHL (at $685 \mathrm{~nm}$ ). Over the study ecosystems, CHL ranged from 3 to $350 \mathrm{\mu g} / 1$, SM - from 2 to $43 \mathrm{mg} / 1$, and DOM absorption coefficient at $380 \mathrm{~nm}$ from 0.1 to $10 \mathrm{~m}^{-1}$. Between different study areas, water quality is quite distinctive. We believe that by using broad range of aquatic ecosystems from oligotrophic to hypertrophic we are able to develop comprehensive optical models and algorithms for remote estimation of water quality.

\section{RESULTS}

The reflectance ( $R$ ) spectrum reveals a low $R$ at the wavelength 430 to $480 \mathrm{~nm}$, which is due to absorption by both algal pigments (e.g. chlorophyll-a) and yellow substance. The minima between 560 and 700 $\mathrm{nm}$ correspond to the absorption maxima of phytoplankton pigments. At $675 \mathrm{~nm}$ a reflectance minimum corresponding to the CHL absorption band is quite clear. These is an increase in reflectance at the wavelengths $560-590 \mathrm{~nm}$, which is the result of low absorption by photosynthetic pigments coupled with an increase in scattering when particle concentration increases. A peak of $R$ is also notable at 685 to $720 \mathrm{~nm}$. In productive waters this maximum may shift and reach $720 \mathrm{~nm}$ when CHL increases to concentrations higher than $100 \mu \mathrm{g} / 1[10,14]$. The result strongly supports the hypothesis: the peak can be explained a minimum in the combined absorption curves of algae and water [10]. 


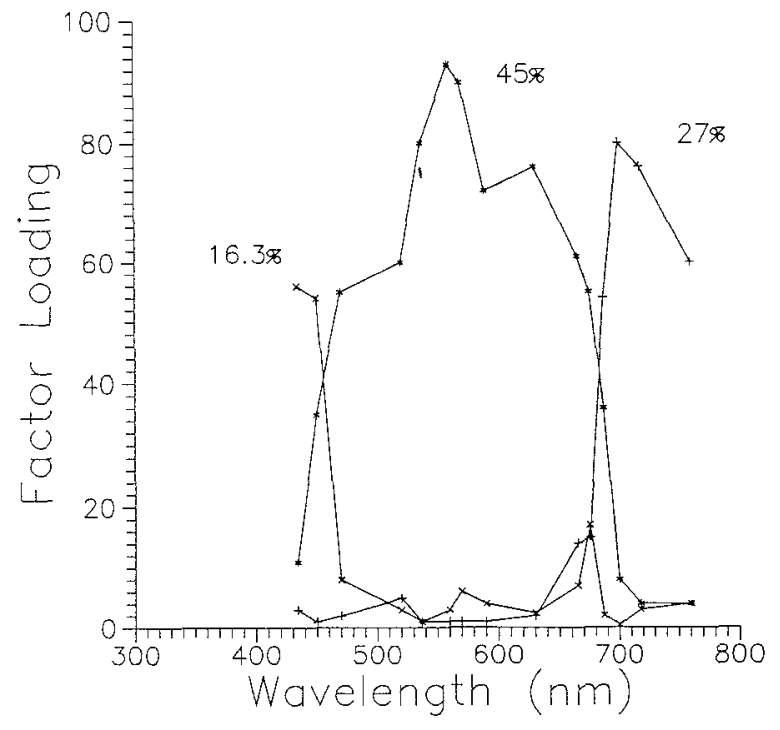

Figure 1. Extracted factor solution and their correlation with spectral channels.

We used factor analysis to identify the independent components that cause variability in the radiance spectrum, as well as the wavelengths, that are sensitive to these factors $[3,4,11]$. The analysis indicates that over $88 \%$ of reflectance dispersion value at the wavelengths 430 to $750 \mathrm{~nm}$ can be accounted for by three factors (Figure 1). The first factor accounts for $16.3 \%$ of the reflectance dispersion, the second factor - $45.3 \%$, and third - $27 \%$. Based on this analysis, we suggest that the spectral bands that are more suitable for the estimation of water quality are 690$710 \mathrm{~nm}$ for $\mathrm{CHL}, 540-590 \mathrm{~nm}$ for $\mathrm{SM}$, and $450-480 \mathrm{~nm}$ for DOM $[7,8]$.

Factor and signature analysis indicates that the reflectance ratio $\mathrm{zk}$ relates to constituent concentrations $\mathrm{Ck}$ satisfactorily by using a relationship of the form:

$$
\mathrm{c}_{\mathrm{k}}=\mathrm{az}^{\mathrm{b}}
$$

For assessment of $\mathrm{CHL}$ and SM concentrations with acceptable accuracy, we recommend the following:

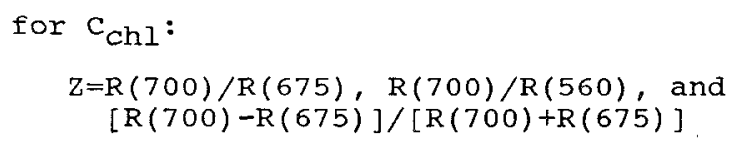

for $c_{S m}$ :

$$
\begin{aligned}
Z= & {[R(560)-R(520)] /[R(560)+R(520)] } \\
& {[R(560)-R(630)] /[R(560)+R(630)], } \\
& \text { and } R(560) / R(520)
\end{aligned}
$$

Development of decoding index for derivation of dissolve organic matter concentration from reflectance spectrum is

\begin{tabular}{|c|c|c|c|c|c|c|}
\hline \multicolumn{2}{|l|}{ Water bodies } & \multicolumn{4}{|c|}{$\mathrm{z}=\mathrm{R}(700) / \mathrm{R}(560)$} & \multirow{2}{*}{$\begin{array}{r}C_{\text {chlavg }} \\
\mu g / 1\end{array}$} \\
\hline & & a & $\mathrm{b}$ & $r$ & $\mathrm{~F}$ & \\
\hline Lake Balaton, & 1985 & 125.21 & 2.32 & 0.95 & 2046 & 48.8 \\
\hline Lake Balaton, & 1986 & 94.63 & 2.19 & 0.95 & 488 & 63.3 \\
\hline Lake Balaton, & 1988 & 68.03 & 2.59 & 0.86 & 101 & 10.2 \\
\hline Lake Mugelzee, & 1986 & 217.02 & 1.84 & 0.95 & 1700 & 101.4 \\
\hline Lake Mugelzee, & 1988 & 196.37 & 1.31 & 0.88 & 820 & 72.3 \\
\hline River Don, & 1983 & 67.36 & 2.84 & 0.97 & 107 & 18.5 \\
\hline River Don, & 1984 & 71.52 & 2.91 & 0.84 & 85 & 12.9 \\
\hline River Donec, & 1983 & 58.56 & 2.25 & 0.98 & 107 & 24.6 \\
\hline River Donec, & 1984 & 72.24 & 2.82 & 0.92 & 118 & 7.9 \\
\hline \multirow{2}{*}{\multicolumn{2}{|c|}{ Water bodies }} & \multicolumn{4}{|c|}{$\mathrm{Z}=\mathrm{R}(700) / \mathrm{R}(675)$} & \multirow{2}{*}{$\begin{array}{r}\mathrm{C}_{\text {chlavg }} \\
\mu \mathrm{g} / 1\end{array}$} \\
\hline & & a & $\mathrm{b}$ & $r$ & $\mathrm{~F}$ & \\
\hline Lake Balaton, & 1985 & 15.64 & 2.95 & 0.96 & 2140 & 48.8 \\
\hline Lake Balaton, & 1986 & 27.94 & 2.28 & 0.96 & 512 & 63.3 \\
\hline Lake Balaton, & 1988 & 13.33 & 3.21 & 0.88 & 115 & 10.2 \\
\hline Lake Mugelzee, & 1986 & 55.70 & 1.75 & 0.98 & 2600 & 101.4 \\
\hline Lake Mugelzee, & 1988 & 66.02 & 3.02 & 0.92 & 1100 & 72.3 \\
\hline River Don, & 1983 & 12.12 & 3.10 & 0.96 & 105 & 18.5 \\
\hline River Don, & 1984 & 10.20 & 3.42 & 0.89 & 98 & 12.9 \\
\hline River Donec, & 1983 & 13.10 & 3.05 & 0.98 & 107 & 24.6 \\
\hline River Donec, & 1984 & 9.32 & 3.41 & 0.96 & 144 & 7.9 \\
\hline
\end{tabular}
rather complicated by the fact that DOM

Table 1. Parameters and statistics of relationships $\mathrm{C}_{\mathrm{ch} 1}=\mathrm{az}$ for different water areas. 

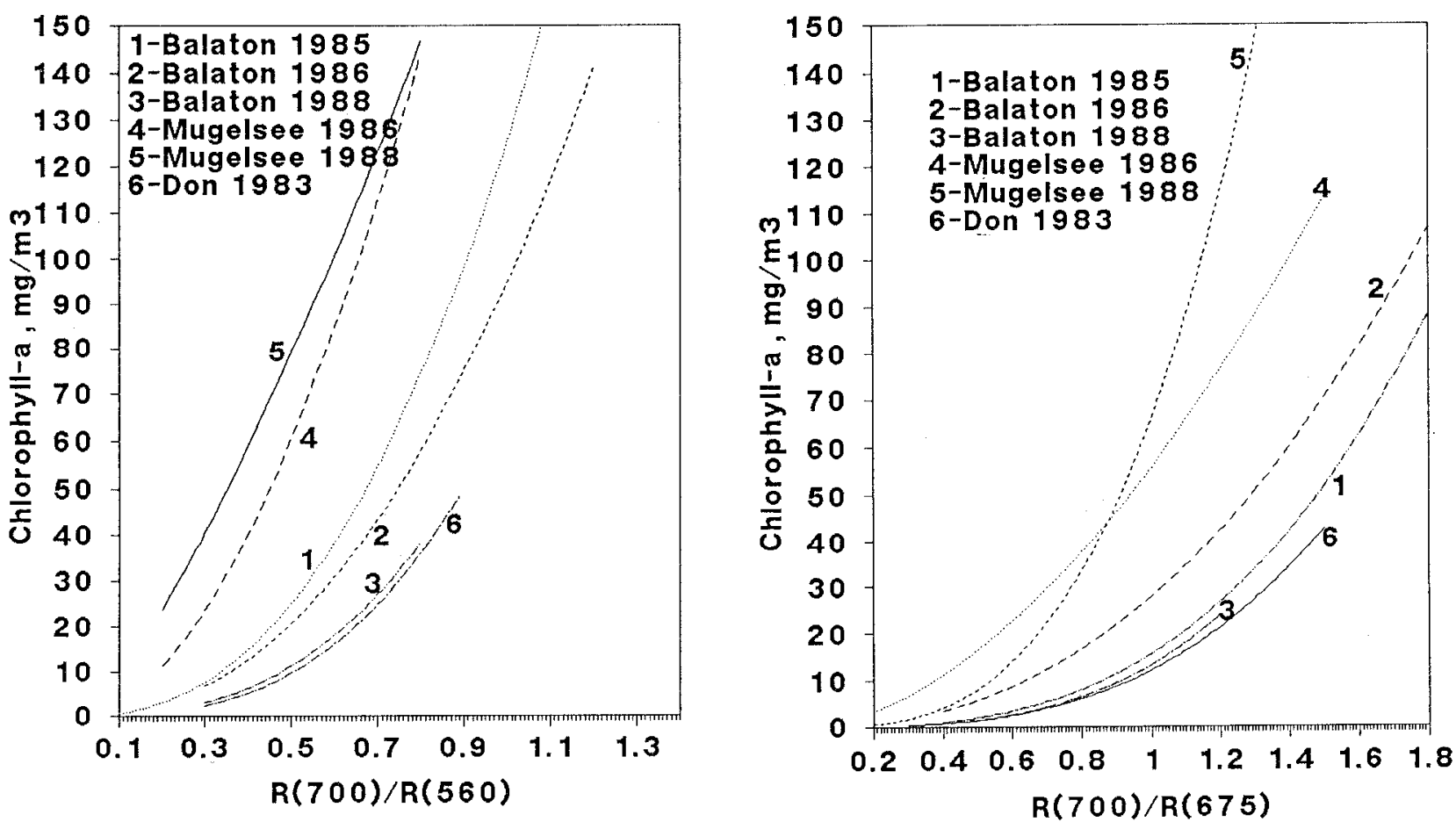

Figure 2. Relationships between CHI concentration and reflectance ratios $R(700) / R(560)$ and $R(700) / R(675)$.

does not have unique spectral feature on radiance spectra. Along with its absorption effect, high portion of the upwelling (ir) radiance at the 430-480 $\mathrm{nm}$ can be contributed to the solar induced fluorescence of dissolved organic matter $[1,8,12]$. Our method of DOM concentration assessment was based on ratio of reflectance at $480 \mathrm{~nm}$ (most sensitive to changes in the DOM concentrations) to reflectance at the reference wavelengths 520 and $630 \mathrm{~nm}$ (least sensitive to changes in the concentrations of water quality components) [11]. As reflectance at $480 \mathrm{~nm}$ depends not only on $\mathrm{C}_{\mathrm{dom}}$ but also on $\mathrm{C}_{\mathrm{chl}}$, influence CHL took into account by using item $\mathrm{kR}(700) / \mathrm{R}(675)$ as first approach. For derivation dissolved organic matter from reflectance spectrum following ratios were used:
$\mathrm{Z}=\{\mathrm{R}(470)+\mathrm{k}[\mathrm{R}(700) / \mathrm{R}(675)]\} / \mathrm{R}(520)$ and

$\{R(470)+k[R(700) / R(675)]\} / R(620)$

Using equation 1 with $2-4$ we had obtained : for CHL correlation coefficient (r) was $r>0.96$ and estimation error $\delta C_{\mathrm{Chl}}<2.5 \mathrm{\mu g} / \mathrm{l}$; for $\mathrm{SM}-\mathrm{r}>0.92$ and $\delta \mathrm{C}_{\mathrm{sm}}<3 \mathrm{\mu g} / \mathrm{l}$; for DOM $-\mathrm{r}>0.90$ and $8 C_{\text {dom }}<0.5 \mu \mathrm{gC} / 1[7,9]$. The parameters of the equation 1 for estimation of $C_{\text {ch }}$ averaged $\mathrm{CHL}$ concentrations $\left(\mathrm{C}_{\mathrm{ch}}\right.$ lavg $)$ for different water areas are shown in Table 1

The relationship between $C_{c h}$ and reflectance ratio varies over different water areas and in the different seasons. Comparing the shape of the curves shown on Figure 2 to an averaged chlorophyli-a concentrations it becomes clearly that the

Table 2. Correlation coefficients of $C_{\text {chl }}$ vs, $R(700) / R(675)$ and $\mathrm{C}_{\mathrm{chl}}$ vs, $\mathrm{R}(700) / \mathrm{R}(560)$ relationships and chlorophyll estimation errors $\left(\delta \mathrm{C}_{\mathrm{Chl}}\right)$ taking averaged values of $\mathrm{CHL}$ into consideration.

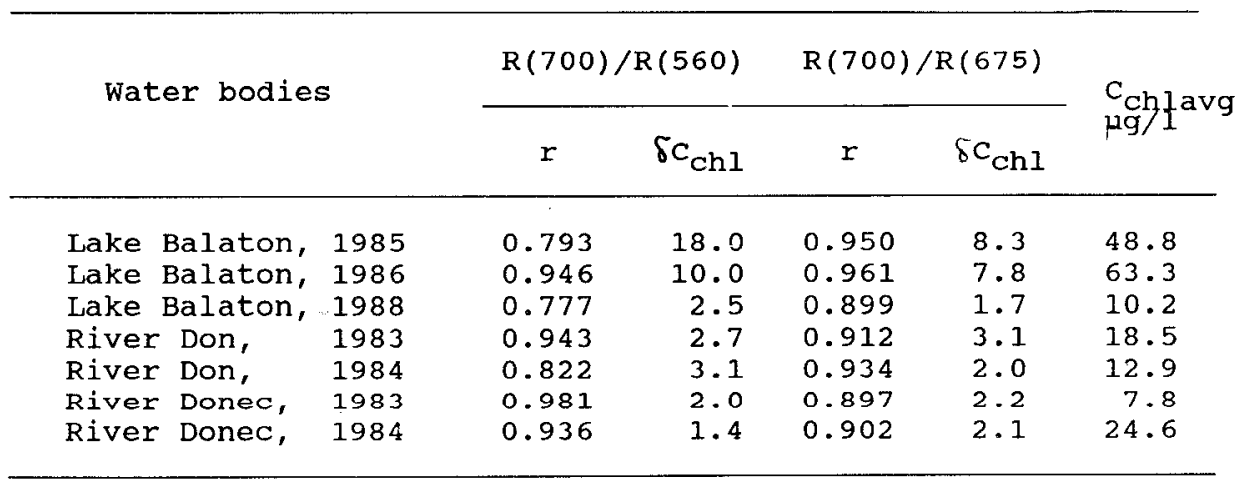


curves tend to shift toward the lower range of ratios $R_{i} / R_{j}$ values, when $C_{\text {chl }}$ increases. This indicates that the position of the curves $C_{C h l}=a\left[R_{i} / R_{j}\right]^{b}$ and values of parameters a and $b$ are determined by the average trophic state of the water body. It is possibly to improve the relationship $\mathrm{C}_{\mathrm{chI}}=\mathrm{a}\left[\mathrm{R}_{i} / \mathrm{R}_{j}\right]^{\mathrm{b}}$ by using correction factors that depend on the averaged $\mathrm{CHL}$ concentration. The estimated CHL concentration is:

$$
\mathrm{c}_{\mathrm{chl}}=\mathrm{a}\left(\mathrm{C}_{\mathrm{chlavg}}\right) \mathrm{z}^{\mathrm{b}(\mathrm{Cchl} \mathrm{avg})}
$$

where the values of $a\left(C_{c h l a v g}\right)$ and $\mathrm{b}\left(\mathrm{C}_{\mathrm{Chlavg}}\right)$ are determined:

for ratio $R(700) / R(560)$ :

$\mathrm{a}=1.46 \mathrm{C}_{\text {chlavg }}+44.25, r=0.91$

$\mathrm{b}=-0.013 \mathrm{C}_{\text {chlavg }}+2.9, \quad \mathrm{r}=-0.89$

for ratio $R(700) / R(675)$ :

$a=0.473 \mathrm{C}_{\text {chlavg }}+1.68, \quad r=0.92$

$b=-0.013 C_{\text {chlavg }}+3.50, \quad r=-0.96$

In Table 2 estimation errors and correlation coefficients are shown.

In order to enable the utilization of existing satellite images for the assessment of water quality, and, to determine if more optimal wave bands might be selected in the future for these purposes, we integrated the data of near surface (ir) radiance measurements with the wavelength domains over which the sensors of the extant satelites work. Normalization of reflectance spectra allowed us to obtain a close relationship of $\mathrm{C}_{\mathrm{chl}}$ with the function of reflectance over wide wavelength bands. The relationships between radiance value, integrated over the bands of the MSS LANDSAT sensors, and $\mathrm{C}_{\mathrm{ch}}$ in the band ratios MSS6/MSS4, MSS4/MSS $4+5+6$ and MSS6/MSS $4+5+6$ proved to be suitable for the remote sensing of $\mathrm{C}_{\mathrm{ch}}$, when observed maximum CHL values fall in the range of 20 $\mu \mathrm{g} / \mathrm{l}<\mathrm{C}_{\mathrm{Chl}}<150 \mu \mathrm{g} / \mathrm{l}$. When $\mathrm{C}_{\mathrm{chl}}<20$ $\mu \mathrm{g} / \mathrm{l}$ it is advisable to consider ratios MSS5/MSS 4 and MSS $4+5+6$ in order to achieve better results [6]. We derived suitable wave bands for the utilization of future space systems NIRIS and MODIS in the assessment of water quality. By using the $480,500,520,560,630,650,675,700$, and $710 \mathrm{~nm}$ wavelengths, estimation errors should be less than $2 \mathrm{~kg} / 1$ for $\mathrm{CHL}, 0.7$ $\mu \mathrm{gC} / \mathrm{l}$ for DOM, and $2.5 \mathrm{mg} / 1$ for $S M$.

\section{REFERENCES}

1. Dirks, R.W.J., "On the Color of the sea (with reference to remote sensing)," Ph.D. Thesis, state University of Utrecht, The Netherlands, 1990, pp.78-81.

2. A.G. Dekker, T.J.Malthus and E. Seyhan, "An Inland Water Quality Bandset for the CAESAR System Based on Spectral Signature Analysis," in proceedings of Int. Symposium "Remote sensing and Water Resources", Enschede, The Netherlands, August 1990, pp. 597-606.
3. R. Doerffer, "Factor Analysis in Ocean Color Interpretation," in J.F.R. Gower (Ed): Oceanography from space, Plenum Press, New York, pp. 339-345, 1981.

4. J. Fischer, R. Doerffer, and H. Grassl, "Factor analysis of multispectral radiances over coastal and open ocean water based on radiative transfex calculations," Appl. Opt., vol. 25, pp. $448-456,1986$.

5. A.A. Gitelson, G.P. Keydan, and V.N Shishkin, "Assessment of. Inland water Quality According to the Multizonal Airspace Imagery," Earth Research from Space, No.6, pp. 28-36, 1985.

6. A.A. Gitelson, A.M. Nikanorov, G.Sabo and F. Szilagyi," Etude le la qualite des esex de surface par teledetection," IAHS publ., vol. 157, pp. 111-121, 1986.

7. A.A. Gitelson and A.M. Nikanorov, "Remote monitoring of Ecological Condition of Aquatic Ecosystems," Fate and Effects of Pollutants an Aquatic organisms and Ecosystems, EPA 600/9-88/001, pp.166-182, 1988 .

8. A.A. Gitelson and G.P.Keydan, "Remote Sensing of Inland water Quality by Measurements in the Visible spectrum, " Acta Hydrophys., vol. 34, pp. 5-27, 1990.

9. A.A. Gitelson, and F.Szilagyi, "Radiomodels of Mesotrophic and Eutrophic Water Bodies," in Proceedings of Int. Symposium "Remote sensing and water Resources", Enschede, The Netherlands, August 1990, pp. 606-616.

10. A.A. Gitelson, K.Ya. Kondrat'ev, "The nature of the maximum at $700 \mathrm{~nm}$ on radiance spectrum and its application for remote monitoring of water quality," Transaction of the USSR Academy of Sciences, Earth science Sections, vol. 306 , pp. $60-63,1989$.

11. K.Ya.Kondrat'ev, G.P., Garbuzov, and A.A. Gitelson, "New approach to the problem of aquatic ecosystems state monitoring according to reflectance spectrum," Transaction of the USSR Academy of Sciences, Earth Science Sections, vol. 295, pp. 39-43, 1987.

12. K.Ya. Kondrat'ev, A.A. Gitelson, and A. Dubovitskij, "Remote sensing of dissolved organic matter in aquatic ecosystem," Transaction of the USSR Academy of Sciences, Earth Science sections, vol. 295, pp.33-36, 1987.

13. K. Mittenzwey, and A.A.Gitelson, "In situ Monitoring of Water Quality on Basis of Spectral Reflectance," Int. Revue ges. Hydrobiol., vol.73, pp. 61-72, 1988.

14. W.L. Vos, M. Donze, and H. Buiteveld, "On the reflectance spectrum of algae in water: The nature of the peak at $700 \mathrm{~nm}$ and its shift with varying concentration," Delf, The Netherlands, 86-22, 1986. 